\title{
EXPLORING SHARED BOOK READING STYLES OF CHINESE TEACHERS FROM THE PERSPECTIVE OF ACTIVITY THEORY
}

\author{
Yanping Su \\ Department of Education, The University of Hong Kong (Hong Kong)
}

\begin{abstract}
Research in shared book reading has revealed that teachers vary in their styles of interacting with children around books, which can affect children's language and literacy development in different ways. While previous studies have identified broad patterns of teacher reading styles, few have defined the term or addressed adequately and systematically how characteristics of children and books help shape these patterns. This study applies activity theory model and conceptualizes teacher reading style as a multidimensional construct inherent in the transactional activity of shared book reading, in which the teacher (as the subject), the children (as the community member), and the book (as the tool) bring their own qualities to condition one other and enact the reading interaction. This conceptualization guides the qualitative inquiry revolving around six preschool teachers from Mainland China in a multiple case study. Data collection includes intensive classroom observation, teacher interview and documentation. Audio-recordings of reading sessions and teacher interviews will be transcribed and coded with qualitative analysis software. A cross-case analysis will be conducted to untangle how teacher reading styles are related to contextual specifics across cases and what learning opportunities for children can be offered through different reading styles. With a fine-grained representation and an in-depth analysis of teacher reading styles, the exploratory study seeks to inform preschool teachers of the possibilities of consciously shifting among reading styles in response to circumstantial requirement, and to provide implications for studies that examine differential effects of teacher reading styles on child development.
\end{abstract}

Keywords: Shared book reading, teacher reading style, activity theory.

\section{Introduction}

Shared book reading, also known as joint book reading, reading aloud, or interactive reading, generally refers to the process in which adults read a book to children and sometimes engage them in book-related discussion (Schickedanz \& McGee, 2010). In classroom context, teachers naturally demonstrate different styles in presenting book information and facilitating discussion, yet our current knowledge about what and how specific aspects of teacher reading style affect certain domains of child development is limited by a relatively small body of research in teacher reading style, compared with that in parent reading style (Cline \& Edwards, 2017). Further, this literature is obscured by a lack of conceptualization of teacher reading style, rendering it difficult to tease out what the construct encompasses and how it interacts with contextual variables. This article aims to address this issue by reviewing prior research and suggesting a sociocultural outlook on teacher reading style. It proposes that teacher reading style be conceptualized as a multidimensional concept best examined in relation to the characteristics of the teacher, the book, the children and relevant elements in the activity system.

\section{Teacher reading style as a multi-dimensional construct}

The extant literature has yet offered an explicit definition of teacher reading style, though it has been used interchangeably with such terms as storybook reading style (Martinez \& Teale, 1993) and read aloud style (Price, Bradley, \& Smith, 2012) in studies that seek to delineate patterns of teacher talk in shared book reading. Dickinson, McCabe and Anastasopoulos (2003) stated that teacher reading styles vary in "when and to what extent they engage children in conversations as they read, in the nature of questions they ask, and in the extent to which their reading includes dramatic qualities" (p.97). This implies that a thorough understanding of teacher reading style entails not only consideration of structural features such as the proportion of discussion in the reading event and the distribution of responsibilities in talk, but also the cognitive flow of verbal exchange and the pedagogical strategies employed by teachers.

Indeed, a closer look on prior research reveals that the majority have utilized these aspects in characterizing teacher reading style. Dickinson and Keebler (1989) identified two reading styles according to varying degrees of discussion: an interactive style in which the teacher engage children in considerable discussion while reading the book, and a performance style in which the teacher provide storytelling with few breaks for discussion. Later studies (e.g. Hindman, Connor, Jewkes, \& Morrison, 2008; Zucker, Cabell, 
Justice, Pentimonti, \& Kaderavek, 2013) went beyond structural level and shifted attention to the pragmatic functions performed by teacher utterances and the cognitive demand placed on preschoolers. Whether teacher utterances serve to provide or request information is indicative of how the labor of talk is shared among the teacher and children, while cognitive demand of teacher talk hints at the types of learning opportunities opened to children. Both can yield useful yet distinctive details for capturing the role of teachers and have thus found their ways into the coding systems of many studies, enabling more subtle differences across reading styles to surface. For example, based on the interactive style, Dickinson (2001) further distinguished a co-constructive style from a didactic-interactional style. While both include discussion, the former features high cognitive demand conversation, the latter low cognitive demand talk such as recall of factual information.

Besides structural, pragmatic and cognitive dimensions, researchers have approached the construct by analyzing how teachers mediate the content and the structure of the book in shared reading. This is exemplified by the work of Martinez and Teale (1993) that examined reading styles of six kindergarten teachers from three facets: the focus of teacher talk (e.g. setting and character), the type of information discussed (e.g. background and inference) and the instructional strategies (e.g. eliciting and reviewing). One merit of operating the construct in this way is that it informs readers as to how specific instructional strategies were associated with various aspects of the book, contributing to case-sensitive knowledge of how reading styles functioned in context. By highlighting the role of instructional strategies in framing discourse patterns, the study added another important dimension to the concept. The underlying assumption is that teacher reading style would be more meaningfully understood when taking into account of the book read and the role of teachers as the mediator between the text and children in shared reading.

\section{Teacher reading style from a socio-cultural perspective}

Another feature of previous studies is that many have proposed labels to characterize reading styles (e.g. Dickinson, 2001; Schick, 2015). While labels can be helpful for differentiation, it risks compromising the complexity of the concept. For one thing, labels are limited in covering the full range of teacher reading style. For another, labels cannot reflect the connection between the construct and contextual factors, such as the book and children. Dickinson et al. (2003) pointed out that book genre, familiarity and complexity can affect what teachers read and how they read it with children. Teachers generally use more inferential questions and engage children in more cognitively challenging discussion when reading informational texts than storybooks (Zucker, Justice, Piasta, \& Kaderavek, 2010). They also adjust cognitive demand of conversation as a function of the age, ability and engagement levels of children (Dickinson, 2001).

Subjective factors also play a part in explaining the variation in teacher reading style. Gerde and Powell (2009) observed that teachers with more years of education and training in early childhood delivered more book-focused talk, while Bratsch-Hines, Vernon-Feagans, Varghese, and Garwood (2017) reported an association between teacher knowledge and experience in reading and their use of meaning-based instructional strategies, suggesting that teacher knowledge, experience and level of education are relevant factors in the equation. Price et al. (2012) argued that teacher enjoyment and confidence in shared book reading could bear on their teaching practices. Although empirical research in this line is scarce, there is evidence on how preschool teachers' belief influences teacher-child interaction (e.g. Garrity \& Guerra, 2015), implying that teacher perception may be a variable worth exploration.

On top of contextual and subjective influence, sometimes teacher reading style needs to be examined against institutional and cultural background. Lipsky and Adelman (2016) found that compared with private school teachers, Head Start teachers employed vocabulary instruction strategies more often in shared book reading, a phenomenon that can be explained by the guidance of Head Start Performance Standards and the monitoring of Head Start district personnel, both placing an emphasis on supporting children's vocabulary development. This indicate that in some cases, teacher reading style can be the product of a deliberate and gradual adjustment of teaching behaviors based on the norms and policies available in the teaching environment that regulate how shared book reading should be implemented.

\section{Teacher reading style from the lens of activity theory}

In line with its socio-cultural outlook, this study draws on activity theory as a descriptive framework for depicting various dimensions of teacher reading style, and as an analytical tool for exploring subjective, contextual and institutional factors that shape the construct. Engestrom (1999) identified six elements in the activity model: subject, object, instrument, rule, community and share of labor (see Figure 1). In the activity system of shared book reading, teacher reading style is conceptualized as entailing the usual ways in which the teacher, as the subject, uses the instrument of books and instructional strategies to engage the community member of children in sharing the labor of achieving the object. Each element may bring in their own qualities to define and condition teacher reading style. For instance, the subject (i.e. the teacher) may differ in qualification and perception, while the community can include children of different age groups or ability levels. Only with a holistic and systematic analysis of how these elements interact within the system can one arrive at a comprehensive understanding of teacher reading style. 
Figure 1. Developing Conceptual Framework from Activity Theory.

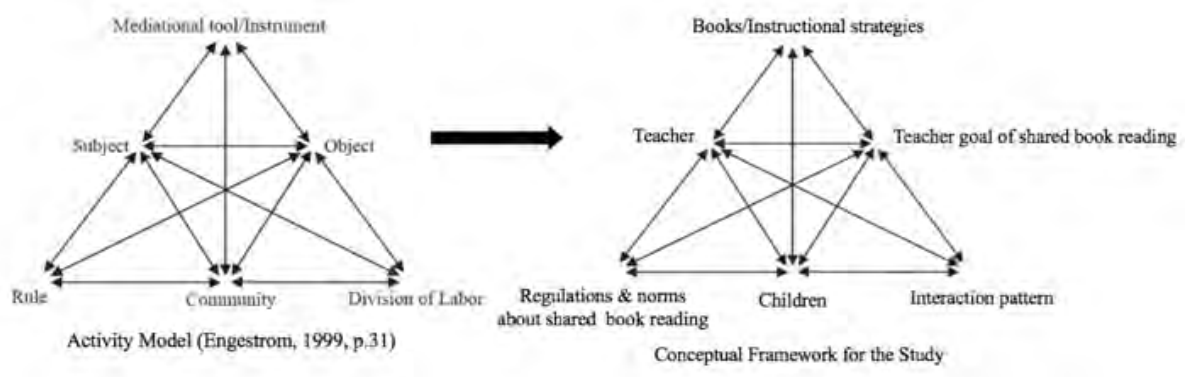

\section{Conclusions}

This article revisits extant literature on teacher reading style and discusses how structural, pragmatic, cognitive and instructional dimensions of shared book reading help circumscribe the construct. The multidimensional nature of teacher reading style defies any simple labels, but demands a socio-cultural perspective that addresses subjective, contextual and institutional influence in a systematic way. The activity model is proposed as a descriptive and analytical framework to explore how teacher reading style is manifested in and shaped by different elements in the activity system of shared book reading.

\section{References}

Bratsch-Hines, M. E., Vernon-Feagans, L., Varghese, C., \& Garwood, J. (2017). Child skills and teacher qualifications: Associations with elementary classroom teachers' reading instruction for struggling readers. Learning Disabilities Research \& Practice, 32(4), 270-283.

Cline, K. D., \& Edwards, C. P. (2017). Parent-child book-reading styles, emotional quality, and changes in early Head Start children's cognitive scores. Early Education and Development, 28(1), 41-58.

Dickinson, D. K., \& Keebler, R. (1989). Variation in preschool teachers' styles of reading books. Discourse Processes, 12(3), 353-375.

Dickinson, D. K., McCabe, A., \& Anastasopoulos, L. (2003). A framework for examining book reading in early childhood classrooms. In A. V. Kleeck, S. A. Stahl \& E. B. Bauer (Eds.), On reading to children: Parents and teachers (pp.95-113). Mahwah, N. J.: Routledge.

Dickinson, D. K. (2001). Book reading in preschool classrooms: Is "recommended practice" common? In D. K. Dickinson \& P. O. Tabors (Eds.), Beginning literacy with language: Young children learning at home and school (pp.175-204). Baltimore: Brookes Publishing.

Engestrom, Y. (1999). Activity theory and individual and social transformation. In Y. Engestrom, R. Miettinen \& R.-M. Punamaki (Eds.), Perspectives on activity theory (pp.19-38). New York: Cambridge University Press.

Garrity, S., \& Guerra, A. W. (2015). A cultural communities approach to understanding Head Start teachers' beliefs about language use with dual language learners: Implications for practice. Contemporary Issues in Early Childhood, 16(3), 241-256.

Gerde, H. K., \& Powell, D. R. (2009). Teacher education, book-reading practices, and children's language growth across one year of Head Start. Early Education and Development, 20(2), 211-237.

Hindman, A. H., Connor, C. M., Jewkes, A. M., \& Morrison, F. J. (2008). Untangling the effects of shared book reading: Multiple factors and their associations with preschool literacy outcomes. Early Childhood Research Quarterly, 23(3), 330-350.

Lipsky, M., \& Adelman, A. (2016). Preschool teachers' implementation of vocabulary strategies during shared reading: A comparative study. Early Education and Development, 27(7), 957-975.

Martinez, M. G., \& Teale, W. H. (1993). Teacher storybook reading style: A comparison of six teachers. Research in the Teaching of English, 175-199.

Price, L. H., Bradley, B. A., \& Smith, J. M. (2012). A comparison of preschool teachers' talk during storybook and information book read-alouds. Early Childhood Research Quarterly, 27(3), 426-440.

Schick, A. (2015). Wordless book-sharing styles in bilingual preschool classrooms and Latino children's emergent literacy skills. Journal of Early Childhood Literacy, 15(3), 331-363.

Schickedanz, J. A., \& McGee, L. M. (2010). The NELP report on shared story reading interventions (Chapter 4) extending the story. Educational Researcher, 39(4), 323-329.

Zucker, T. A., Cabell, S. Q., Justice, L. M., Pentimonti, J. M., \& Kaderavek, J. N. (2013). The role of frequent, interactive prekindergarten shared reading in the longitudinal development of language and literacy skills. Developmental Psychology, 49(8), 1425.

Zucker, T. A., Justice, L. M., Piasta, S. B., \& Kaderavek, J. N. (2010). Preschool teachers' literal and inferential questions and children's responses during whole-class shared reading. Early Childhood Research Quarterly, 25(1), 65-83. 